\title{
ACRL in Philadelphia A wrap-up of ACRL 2011
}

$\mathbf{M}$ ore than 5,300 library staff, exhibitors, speakers, and guests from around the world met from March 30-April 2 in Philadelphia and online for ACRL 2011. Combined with the more than 440 people participating online in the Virtual Conference, ACRL 2011 had the highest combined registrant participation ever for an ACRL conference, with 3,533 face-toface and virtual attendees from all 50 states and 24 other countries.

The med "A Declaration of Interdependence," the conference offered more than 300 programs that explored the interdependency that exists in academic and library communities and the changing nature and role of academic and research librarians. Key issues included future of academic libraries, top technology trends,

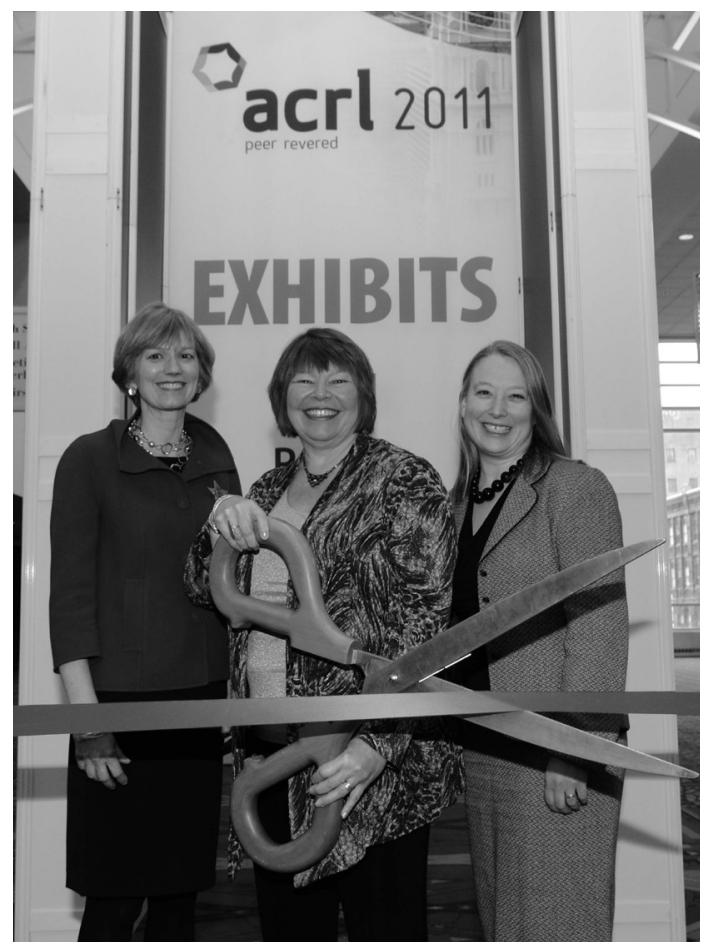

ACRL Executive Director Mary Ellen Davis, ACRL 2011 Conference Chair Pamela Snelson, and ACRL President Lisa Hinchliffe cut the ribbon to open exhibits. facilitating innovative research projects," said ACRL President Lisa Janicke Hinchliffe. "The conference has given academic librarians a broader outlook on the current, changing, and future needs of their faculty and students. More importantly, the conference has given them fresh ideas and inspiration to bring back to their institutions."

Attendees who arrived early had their choice of five preconferences that ranged in topics from video creation and advocacy to theories on change management. More than 500 others participated in the firsttimer orientation (ACRL 101), which included information about how to get more involved in ACRL and how to make the most out of their conference experience.

Another early event was the ACRL Battle Decks open access publishing, distance learning, and information literacy.

"College and research librarians are partners in educating students, offering new perspectives, developing curricula and

tournament, during which speakers presented PowerPoint presentations they had never seen before. Approximately 200 attendees had a chance to experience "PowerPoint karaoke." 
Opening the conference was awardwinning filmmaker, activist, and Webby Awards founder Tiffany Shlain. During the opening keynote session, Shlain discussed the interconnectedness of humankind, nature, and morality of the 21 st century. Immediately before her address, Shlain held a screening of her most recent film, Connected: An Autoblography about Love, Death E Technology," for a standing room only crowd.

Activist and academic Raj Patel, presented a keynote session on the idea of interdependence. Known internationally as an authority on the world economic system and the international food crisis, Patel discussed how growing global "interdependence" impacts the sharing and dissemination of information and ways in which the library profession can support global equality and social justice.

During a session titled "Value of Ac-

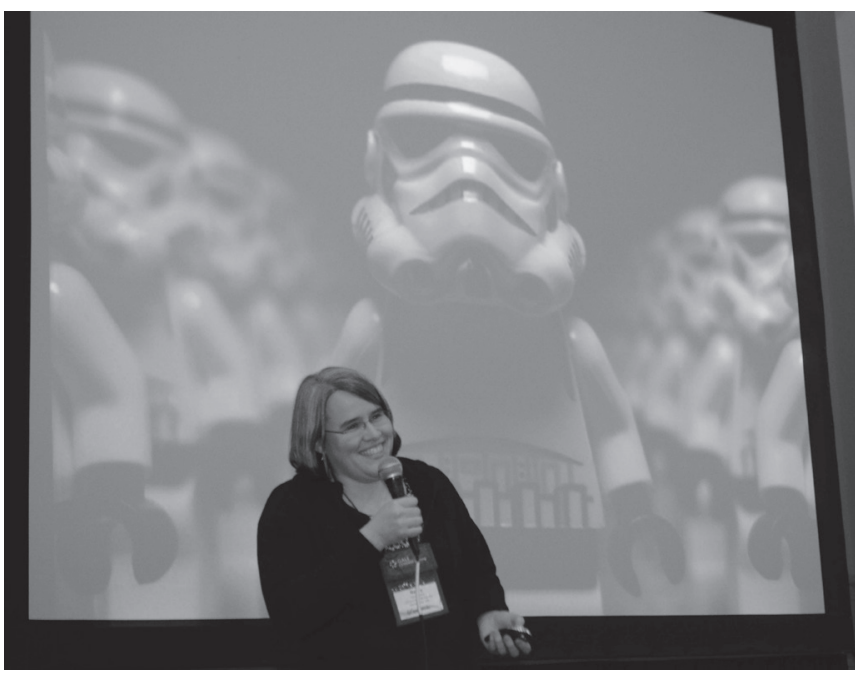

Battle Decks winner Nancy Sims of the University of Minnesota. steps in helping to develop new competencies and strategies.

New to the conference this year was the IdeaPower Unconference, a forum for the exploration of powerful ideas to transform academic libraries. Designed to be an exercise in the dynamic presentation of powerful ideas, approximately 20 presenters volunteered to share an idea with the power to transform academic libraries in a six-minute presentation. Attendees were able to engage with each other, offer feedback on the ideas and presentations and initiate collaborative projects with both like and unlike minds.

ACRL continued its focus on new technologies by offering mobile conference schedules as well as SMS updates; a "text an expert service;" and an increased presence on Twitter through general conference, invited paper, panel, and Cyber Zed Shed session ademic Libraries," panelists discussed findings from "The Value of Academic Libraries: A Comprehensive Review and Report" and how it can be used to position academic librarians as contributors to campus conversations on accountability and impact.

The report provides academic librarians with a clearer understanding of what research about the performance of academic libraries already exists, where gaps in this research occur, and how to identify the most promising best practices and measures correlated to performance. Also discussed were the implications and next hashtags. Attendees were also able to check in at various ACRL 2011 locations via Foursquare for fun and exciting giveaways.

ACRL poster sessions proved to be as popular as ever with attendees jam-packed

\section{ACRL 2011 proceedings}

ACRL 2011 proceedings are freely available online at www.ala.org/ala/mgrps/divs/acrl /events/national/2011/papers/index.cfm. Print copies are also available for purchase through Amazon.com. 
in the extra-wide aisles to view and discuss the 163 posters that were presented. These informed presentations featured successful solutions to problems and library-based projects, with important lessons for the academic and research library community. Topics included assessment, navigation of plagiarism, and copyright laws; instruction design; branding and outreach; project evaluation; emerging technology use and tools; communicating with adult or distance learners; project evaluation; and more.

The morning after the All-Conference Reception at the National Constitution Center, conference attendees were also treated to a keynote session headlined by computer scientist, Internet pioneer, and author Jaron Lanier.

His presentation titled "The Bipolar Library: How Humanizing and Digitizing Must Both Be Advanced" discussed how libraries can stay relevant in the long term:

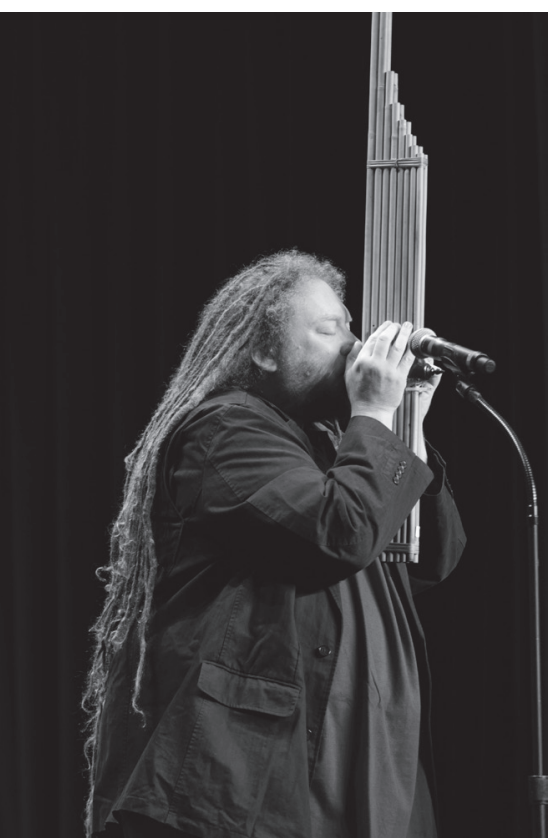

Keynote speaker Jaron Lanier playing a Laotian khaen. through emphasizing the human side of the library and the important work of librarians and by maintaining digital artifacts, such as scientific and scholarly data.

Lanier said that methods and simulations tend to be forgotten or unusable without proper care and that librarians can play a unique role of ensuring that the replication of results and scientific method can be extended into the Internet age.

Clinton Kelly, renowned fashion expert and host of TLC's What Not to Wear, brought the conference to a close with a discussion about engaging change and how to turn any fear into positive action. Kelly's talk provided an inspirational close to a conference that energized academic and research librarians to take the messages, ideas, and stories learned in Philadelphia back to their institutions for a better self and a better library.

Throughout the conference, ACRL partnered with Clean the World in a social responsibilities recycling effort to aid the Cholera outbreak in Haiti. Each day, the Philadelphia Marriott housekeeping department collected gently used amenities throughout the ACRL 2011 headquarters hotel. These bathroom amenities will be repurposed using environmentally friendly and hygienically safe recycling practices. The recycled soap products will then be distributed along with educational materials to help sustain good personal hygiene practices and prevent the spread of diseases.

The exhibit hall was filled with more than 225 exhibiting companies, including top book publishers, featuring state-of-the-art products and services for academic and research libraries. The next ACRL Conference will be held April 10-13, 2013, in Indianapolis. $\boldsymbol{n}$

\section{ACRL 2011 virtual conference}

Access to the ACRL 2011 Virtual Conference-featuring podcasts, live Web casts and slidecasts, PowerPoint presentations synced with real-time audio from every contributed paper, Cyber Zed Shed presentation, invited paper, and panel session presented in Philadelphia-is available to all face-to-face and virtual registrants through April 2012. 